\title{
Janeway Lesion and Splinter Haemorrhages, Old signs Revisited: Cutaneous Stigmata of Cardiac Disorder
}

\author{
Santosh Kumar Sinha, Mukesh Jitendra Jha, Puneet Aggarwal, Vikas Mishra \\ Department of Cardiology, LPS Institute of Cardiology, GSVM Medical College, Kanpur, UP, India.
}

\section{Corresponding Author:}

Dr. Santosh Kumar Sinha

Email: fionasan@rediffmail.com

This is an Open Access article distributed under the terms of the Creative Commons Attribution License (creativecommons.org/ licenses/by/3.0).

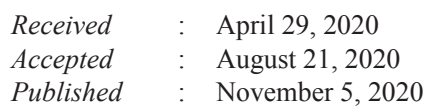

\begin{abstract}
Background: Cutaneous stigmata (Janeway lesion and splinter haemorrhages) are rarely seen in acute infective endocarditis (IE) and serve as an important clue to its early diagnosis and prompt treatment. Case Report: A 20-year-old male presented with intermittent, high grade fever of 2 weeks duration, palpitation and worsening dyspnea. On examination, Janeway lesions and splinter haemorrhages were noted. Echocardiogram revealed large, mobile echogenic mass attached to ventricular surface of right coronary cusps which was perforating the valve causing acute severe aortic leak. He underwent successful aortic valve replacement. Conclusion: These cutaneous lesions may be rarely seen in acute IE and serve as an important clue to IE as prognosis is grave because of high morbidity and mortality and therefore, early diagnosis and prompt treatment may be life saving.
\end{abstract}

Keywords: Aortic Valve Insufficiency, Bacterial Endocarditis, Dyspnea, Echocardiography, Heart Valve Prosthesis.

\section{Case Discussion}

A 20-year-old male presented with intermittent, high grade fever of 2 weeks' duration and palpitation with progressively worsening dyspnea. On examination, he had tachycardia, pulsus bisferiens and early diastolic decrescendo murmur along left sternal border suggestive of aortic regurgitation (AR). There were irregular, erythematous, flat, painless macules on tips of fingers and palms and plantar surfaces of toes and soles [Fig.1] for past one week which were diagnosed as Janeway lesions. Linear blackishbrown streaks were also noted on distal portions of great toes and nail plates of few fingers, which were diagnosed as splinter hemorrhages. Transrthoracic echocardiogram revealed large, mobile echogenic mass $(10 \times 19 \mathrm{~mm})$ attached to ventricular surface of right coronary cusps which

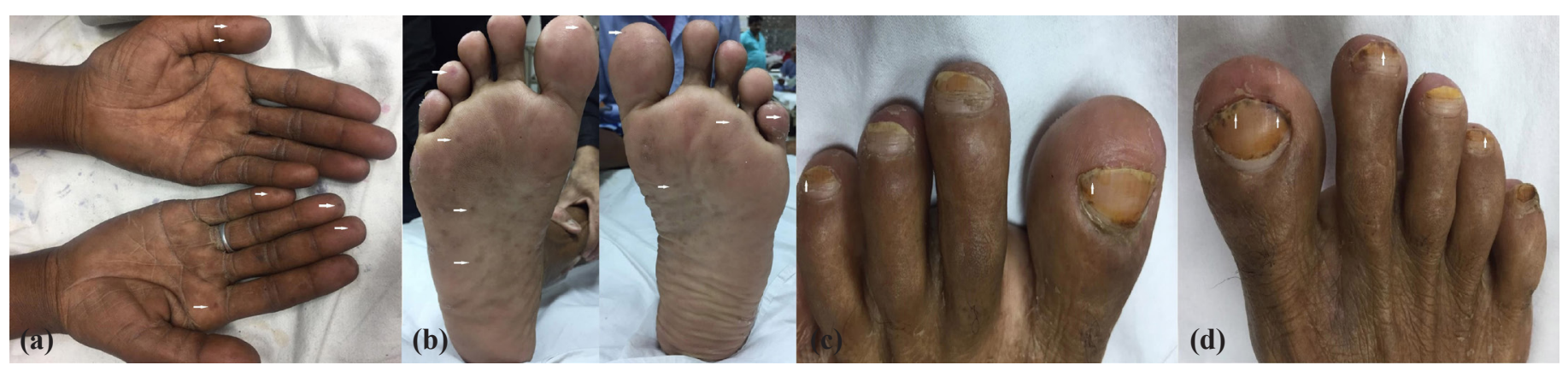

Fig.1: Janeway lesions (white horizontal arrows) as irregular, erythematous, flat, painless macules on plantar surfaces of toes and soles. 


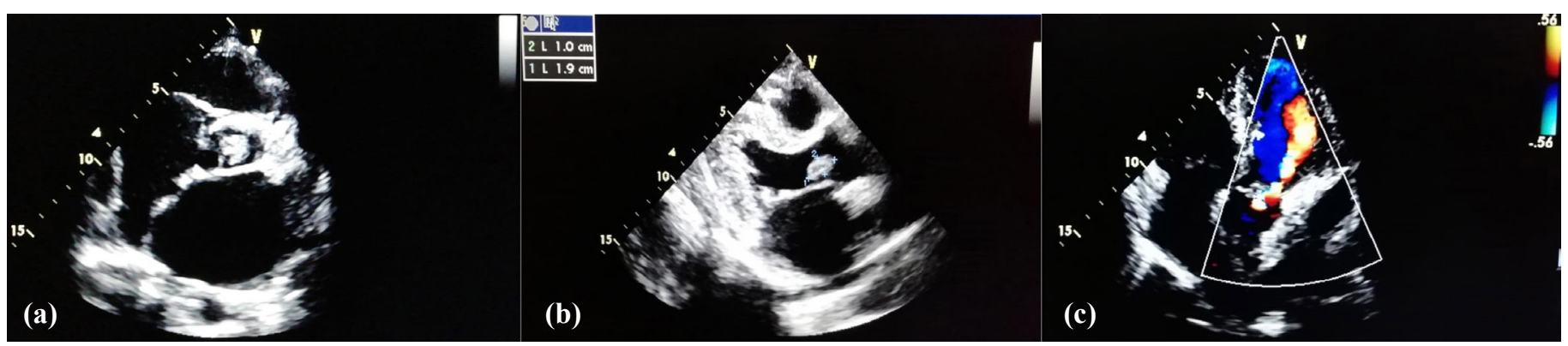

Fig.2: Transthoracic echocardiogram revealed large, mobile echogenic mass attached to ventricular surface of right coronary cusps which was perforation the valve causing severe aortic regurgitation.

was perforating the valve causing severe leak [Fig. 2]. Based on these findings, he was diagnosed to have acute severe AR with infective endocarditis having cutaneous stigmata of Janeway lesions and splinter haemorrhages. Broad spectrum antibiotics were started and he underwent successful aortic valve replacement after getting his informed consent.

Janeway lesions, initially believed to be small-vessel vasculitis, are result of minute septic emboli which stems from valvular vegetations leading to formation of dermal micro abscesses with thrombosis [1]. Splinter haemorrhages are tiny blood clots that run vertically under the nails. They are non-specific cutaneous markers of endocarditis as have been reported in various connective tissue disorders, anti-phospholipid syndrome, hematological malignancy, and trauma [2]. These cutaneous stigmata are seldom seen now as most of IE are diagnosed and treated early but still serve as important diagnostic clue to serious cardiovascular disturbance.

\section{References}

1. Alpert JS. Osler's nodes and Janeway lesions are not the result of small-vessel vasculitis. Am J Med. 2013;126:843-844.

2. Tosti A, Iorizzo M, Piraccini BM, Starace M. The nail in systemic diseases. Dematol Clin. 2006;24:341-347. 